\title{
Analytical Study of Solitary Nodules of Thyroid in Adults: A Clinical, Histopathological and Surgical Management
}

\author{
T. Henry Prabakaran ${ }^{1}$, P. Rajeswari ${ }^{2}$, R. Saminathan ${ }^{3}$, S. Sachithanantham ${ }^{4}$ \\ ${ }^{1}$ Asst.Professor of Surgery, IRT-Perundurai Medical College \& Hospital, Perundurai, Tamilnadu, India \\ ${ }^{2}$ Asst.Professor of Pathology, IRT-Perundurai Medical College \& Hospital, Perundurai, Tamilnadu, India \\ ${ }^{3}$ Professor, Department of General Surgery, Government Mohan Kumaramangalam Medical College, Salem, Tamilnadu, India \\ ${ }^{4}$ Chief Librarian, IRT-Perundurai Medical College \& Hospital, Perundurai,Tamilnadu, India
}

\begin{abstract}
Solitary nodule of thyroid can exhibit various pathology like adenoma cyst thyroiditis lymphoma and thyroid carcinoma. Objective: The aim and objective of this study to find out incidence and prevalence of solitary nodule of thyroid in semi urban regions. Clinical data, various presentation of swelling, clinical symptoms and signs to study the correlative findings of pre FNAC and post operative histopathology examination and study the intra operative and post operative complications. Study design: Descriptive analytical study of 100 adult patients present with solitary nodules of thyroid to evaluate the prevalence of thyroid nodules, clinical data, FNAC, and histopathology examination and study the laboratory values were entered and anlaysed most cases hemithyroidectomy done; and confirmed by $\mathrm{HPE}$.
\end{abstract}

Keywords: Dominant Nodule, FNAC, Clinical Data Histopathology Examination Thyroidectomy, Ultra Scan malignant tumor laboratory values

\section{Introduction}

Thyroid swellings are common in OP and IP patients. Solitary nodule of thyroid is the commonest presentation in surgical wards. It consists of various pathology like adenomas, cysts, carcinomas, dominant nodule, thyroiditis, lymphoma,etc

These nodules present an unilateral thyroid enlargement with normal or hyperfunction. Size of the nodule may be small, $1 \mathrm{~cm}-1.5 \mathrm{~cm}$ in diameter which is difficult to palpate clinically or it may attains huge enlargement clinically producing tracheal compression and various pressure symptoms on vital structures in neck.

Benign adenomas, malignant tumours (papillary, follicular, medullary ca, lymphomas), Thyroiditis, colloid nodules , cysts are identified by various pathological findings.

Clinical examination, Thyroid profile, Fine Needle Aspiration Cytology, HPE, Ultrasound Examination of neck, Indirect Laryngoscopy, X-rays of Chest and neck are the various methods for preoperative workups.

Hemithyroidectomy and total thyroidectomy are the surgeries done for solitary nodule thyroid based on pre operative FNAC reports whether benign or malignant. FNAC cannot differentiate follicular adenoma from follicular carcinoma and they are treated by total thyroidectomy

\section{Aims \& Objectives of the Study}

This study was mainly to analyze the clinically presenting solitary nodular thyroid swellings which commonly present in flurosis prevalent and endemic thyroid region.

The study was conducted in the following disciplines:

1) The incidence and prevalence of the solitary nodule thyroid in and around semi-urban region

2) To study the various presentations of these swellings presenting clinical symptoms and signs and the clinically diagnosed solitary nodules thyroid in which there are clinically in apparent nodules confirmed by FNAC or intraop findings

3) To study the correlative findings in pre-op FNAC and postoperative biopsy reports, intra-operative findings and post operative complications in solitary nodule thyroid and the investigation modalities used

\section{Materials and Methods}

\subsection{Materials}

In this study, a total of 100 cases were taken who satisfied the inclusion \& exclusion criteria Of the 100 patients who underwent our study, there are 10 males and 90 females showing female preponderance $($ sex ratio $=\mathrm{M} ; \mathrm{F} \quad 1 ; 10$ ). There were patients ranging from lowest age of 19 yrs to highest age of 65 years. Written \& Informed consent obtained in their vernacular language

\section{Methods}

Clinical data, regarding thyroid nodule, Laboratory values were entered \& analysed. FNAC \& USG and Histopathology reports were correlated. 


\section{International Journal of Science and Research (IJSR) \\ ISSN (Online): 2319-7064}

Index Copernicus Value (2015): 78.96 | Impact Factor (2015): 6.391

Treatment planning was done as appropriate depending on clinical findings and investigation results. Patients underwent surgery. Postoperative complications were recorded. All patients were followed up for a period ranging from 1 to 7 months.

\section{Anatomy of Thyroid}

- The thyroid gland consists typically of two lobes, a connecting isthmus, and an ascending pyramidal lobe. A minute epithelial tube or fibrous cord, the thyroglossal duct, almost always extends between the thyroid gland and the foramen cecum of the tongue.

- The thyroid gland normally extends from the level of the 5 th cervical vertebra to the body of the 1 st thoracic vertebra

- The normal thyroid gland weighs about $30 \mathrm{~g}$ in the adult. Each lobe is approximately $5 \mathrm{~cm}$ in length, $3 \mathrm{~cm}$ at its greatest width, and $2-3 \mathrm{~cm}$ thick. The isthmus connecting the two lobes is about $1.3 \mathrm{~cm}$ in breadth

\section{Capsule of the Thyroid Gland}

- Thyroid gland has a connective tissue capsule which is continuous with the septa, and which makes up the stroma of the organ. This is the true capsule of the thyroid.

- External to the true capsule is a layer of fascia derived from the pretracheal fascia. This is the false capsule, also called the perithyroid sheath or surgical capsule.

- There is a thickening of the fascia that fixes the back of each lobe to the cricoid cartilage. Such thickenings are the ligaments of Berry

- The superior parathyroid glands normally lie between the true capsule of the thyroid and the fascial false capsule. The inferior parathyroids may be between the true and false capsules, within the thyroid parenchyma, or lying on the outer surface of the fascia.

\section{Superior Thyroid Artery}

- The superior thyroid artery arises from the external carotid artery .It passes downward and anteriorly to reach the superior pole of the thyroid gland.

- In part of its course, the artery parallels the external branch of the superior laryngeal nerve which supplies the cricothyroid muscle and the cricopharyngeus muscle, the lowest voluntary part of the pharyngeal musculature

- At the superior pole, the superior thyroid artery divides into anterior and posterior branches. The anterior branch anastomoses with the contralateral artery; the posterior branch anastomoses with branches of the inferior thyroid artery

- From the posterior branch, a small parathyroid artery passes to the superior parathyroid gland

\section{Investigations}

\section{1) Tests of Thyroid Function}

\section{Serum TSH}

The tests for serum TSH (normal 0.5 to $5 \mathrm{U} / \mathrm{mL}$ ) TSH assay has become the most sensitive and specific test for the diagnosis of hyper- and hypothyroidism and for optimizing $\mathrm{T}_{4}$ replacement and suppressive therapy.
Total $\mathbf{T}_{4}$ and Total $\mathbf{T}_{3}$

Total $\mathrm{T}_{4}$ (reference range: 55 to $150 \mathrm{nmol} / \mathrm{L}$ ) and $\mathrm{T}_{3}$ (reference range: 1.5 to $3.5 \mathrm{nmol} / \mathrm{L}$ ) levels are measured by radioimmunoassay ${ }^{10,11}$ and measure both the free and bound components of the hormones. Total $\mathrm{T}_{4}$ levels reflect the output from the thyroid gland, whereas $\mathrm{T}_{3}$ levels indicative of peripheral thyroid hormone metabolism. ${ }^{5}$ Total $\mathrm{T}_{4}$ levels are increased also in those patients with elevated thyroglobulin levels secondary to pregnancy, estrogen/progesterone use, or congenital diseases. Similarly, total $\mathrm{T}_{4}$ levels decrease in hypothyroidism and in patients with decreased thyroglobulin levels caused by anabolic steroid use and by protein-losing disorders such as nephrotic syndrome. Individuals with these latter disorders may be euthyroid if their free $\mathrm{T}_{4}$ levels are normal. Measurement of total $\mathrm{T}_{3}$ levels is important in clinically hyperthyroid patients with normal $\mathrm{T}_{4}$ levels, who may have $\mathrm{T}_{3}$ thyrotoxicosis.

\section{Free $T_{4}$ and Free $T_{3}$}

These radioimmunoassay-based tests are a sensitive and accurate measurement of biologically active thyroid hormone. Free $\mathrm{T}_{4}$ (reference range: 12 to $28 \mathrm{pmol} / \mathrm{L}$ ) Use of this test is confined to cases of early hyperthyroidism in which total $\mathrm{T}_{4}$ levels may be normal but free $\mathrm{T}_{4}$ levels are raised. Free $\mathrm{T}_{3}$ (reference range: 3 to $9 \mathrm{pmol} / \mathrm{L}$ ).

Free $T_{4}$ levels may also be measured indirectly using the $T_{3}$ resin-uptake test. If free $\mathrm{T}_{4}$ levels are increased, fewer hormone-binding sites are available for binding radiolabeled $\mathrm{T}_{3}$ that has been added to the patient's serum. Therefore, more $T_{3}$ binds with an ion-exchange resin and the $T_{3}$ resin uptake is increased.

\section{Thyrotropin-Releasing Hormone}

This test is useful to evaluate pituitary TSH secretory function and is performed by administering $500 \mathrm{~g}$ of TRH intravenously and measuring TSH levels after 30 and 60 minutes. In a normal individual, TSH levels should increase at least $6 \mathrm{IU} / \mathrm{mL}$ from the baseline.

\section{Thyroid Antibodies}

Thyroid antibodies include antithyroglobulin (anti-Tg), antimicrosomal or antithyroid peroxidase (anti-TPO) and thyroid-stimulating immunoglobulin (TSI). Anti-Tg and anti-TPO antibody levels indicate the underlying disorder, usually an autoimmune thyroiditis.

Approximately $80 \%$ of patients with Hashimoto's thyroiditis have elevated thyroid antibody levels, but levels may also be increased in patients with Graves' disease, multinodular goiter, and, occasionally, with thyroid neoplasms.

\section{Serum Thyroglobulin}

Increases dramatically in destructive processes of the thyroid gland, such as thyroiditis or overactive states such as Graves' disease and toxic multinodular goiter.

The most important use for serum thyroglobulin levels is in monitoring patients with differentiated thyroid cancer for recurrence, particularly after total thyroidectomy and radioactive iodine ablation. 


\section{International Journal of Science and Research (IJSR) \\ ISSN (Online): 2319-7064 \\ Index Copernicus Value (2015): 78.96 | Impact Factor (2015): 6.391}

Fine-Needle Aspiration Biopsy

A 23-gauge needle is inserted into the thyroid mass, and several passes are made while aspirating the syringe. After releasing the suction on the syringe, the needle is withdrawn and the cells are immediately placed on prelabeled dry glass slides; some are immersed in a $70 \%$ alcohol solution, while the others are air dried.

The slides are stained by Papanicolaou ${ }^{21}$ (Pap) or Wright's stains $^{11,13}$ and examined under the microscope. If a bloody aspirate is obtained, the patient should be repositioned in a more upright position and the biopsy repeated with a finer (25- to 30-gauge) needle. After FNA biopsy, the majority of nodules can be categorized into the following groups: benign $(65 \%)$, suspicious $(20 \%)$, malignant $(5 \%)$, and nondiagnostic $(10 \%)$.

The incidence of false-positive results ${ }^{12}$ is approximately $1 \%$ and false-negative results occur in approximately $3 \%$ of patients. If a biopsy is reported as nondiagnostic, it should usually be repeated. Bloody FNA biopsy may also be reported as nondiagnostic and often indicates a follicular neoplasm. Benign lesions include cysts and colloid nodules. The risk of malignancy in this setting is less than $3 \%$. The risk of malignancy ${ }^{15}$ in the setting of a suspicious cytology is anywhere from 10 to $20 \%$. Most of these lesions are follicular or Hürthle cell neoplasms. In this situation, diagnosis of malignancy relies on demonstrating capsular or vascular invasion, features that cannot be determined via FNC biopsy. FNA biopsy ${ }^{18}$ is also less reliable in patients who have a history of head and neck irradiation or a family history of thyroid cancer, because of a higher likelihood of multifocal lesions.

\section{2) Thyroid Imaging}

\section{Radionuclide Imaging}

Ultrasound It is helpful in the evaluation of thyroid nodules, distinguishing solid from cystic ones, and providing information about size and multicentricity.

CT/MRI Scan These studies provide excellent imaging of the thyroid gland and adjacent nodes, and are particularly useful in evaluating the extent of large, fixed or substernal goiters and their relationship to the airway and vascular structures.

\section{Pathology \& Physiology}

The hormones thyroxine (T4) and triiodothyronine (T3) are formed in the epithelial cells (thyrocytes) that surround the follicles of the thyroid gland. Iodine is taken from the blood into the follicular epithelial cells by means of a transporter coupled to $\mathrm{Na}+$. At the apical membrane of the cells it passes into the follicular lumen by exocytosis and is oxidized there. A tyrosine-rich protein ${ }^{1}$ (thyroglobulin, TG) is formed in the epithelial cells and secreted into the follicular lumen. Here the tyrosine residues of the globulin are iodized to the residues of diiodotyrosine (DIT) or of monoiodotyrosine (MIT). The thyroid hormones ${ }^{2}$ are stored as thyroglobulin colloid in the follicular lumen One iodine is removed from $\mathrm{T} 4$ in the periphery by a deiodinating enzyme (deiodinase) and thus converted into the more active T3

\section{Regulation}

Formation and release of $\mathrm{T} 3$ and $\mathrm{T} 4$ as well as growth of the thyroid gland are stimulated by thyrotropin ${ }^{2}$ (TSH) from the anterior pituitary. Its release is, in turn, stimulated by thyroliberin (TRH) from the hypothalamus. Stress and estrogens increase TSH release, while glucocorticoids, somatostatin, and dopamine inhibit it

Enlargement of the thyroid gland (goitre) is the result of uncontrolled growth (tumor), or of increased stimulation by TSH or TSI. In this situation release of thyroid hormones can either be reduced (e.g., in marked iodine deficiency and the above-mentioned enzyme defects) or increased (e.g., in Graves‘ disease).

In Grave's disease: retrobulbar inflammation/ Exophthalmos $^{1,2}$ Light sensitivity, Diplopia Stimulation of the heart Oxygen consumption ,Stimulation of intestinal musculature Bone metabolism- Osteoporosis Hypercalcemia Hypercalciuria

\section{Solitary Thyroid Nodule}

\section{Causes of Thyroid Nodules}

Benign; Multinodular goiter ,Hashimoto's thyroiditis , Simple or hemorrhagic cysts, Follicular adenomas Subacute thyroiditis.

\section{Malignant: Papillary carcinoma ,Follicular carcinoma ,Hürthle cell carcinoma, Medullary carcinoma, Anaplastic carcinoma ,Primary thyroid lymphoma}

Metastatic malignant lesion: Most patients with thyroid nodules are asymptomatic,occasionally patients complain of dysphagia, dysphonia,pressure, pain, or symptoms of hyperthyroidism or hypothyroidism ${ }^{10,11,13}$. Absence of symptoms does not rule out a malignant lesion. Thyroid US should not be performed as a screening test. All patients with a palpable thyroid nodule, however, should undergo US examination.US-guided FNA (US-FNA) is recommended for nodules $\geq 10 \mathrm{~mm}$; US-FNA is suggested for nodules $<10$ $\mathrm{mm}$ onlyif clinical information or US features are suspicious

Patients with benign thyroid nodules should undergo followup, and malignant or suspicious nodules should be treated surgically. A radioisotope scan of the thyroid is also useful.

\section{Family History}

A family history of thyroid cancer is a risk factor for the development of both medullary and nonmedullary thyroid cancer. Familial medullary thyroid cancers occur in isolation or in association with other tumors as part of multiple endocrine neoplasia type 2 (MEN2) syndromes. 


\section{International Journal of Science and Research (IJSR) \\ ISSN (Online): 2319-7064}

Index Copernicus Value (2015): 78.96 | Impact Factor (2015): 6.391

\section{Diagnostic Tests}

Fine-Needle Aspiration Biopsy

This procedure has become the single most important test in the evaluation of patients with thyroid masses and can be performed with or without ultrasound guidance. ${ }^{17,18}$

Ultrasound guidance is recommended for nodules that are difficult to palpate and for complex, solid cystic nodules that recur after the initial aspiration. ${ }^{24}$

\section{Laboratory Studies}

Most patients with thyroid nodules are euthyroid. Determining the blood TSH level is helpful. If a patient with a nodule is found to be hyperthyroid, the risk of malignancy is approximately $1 \%$.

Serum Tg levels cannot differentiate benign from malignant thyroid nodules unless the levels are extremely high, in which case metastatic thyroid cancer should be suspected. Thyroglobulin levels are, however, useful in following patients who have undergone total thyroidectomy for thyroid cancer and also for serial evaluation of patients undergoing nonoperative management of thyroid nodules. Serum calcitonin levels are also done in MTC cases and also tested for RET oncogene mutations and have a 24-hour urine collection with measurement of levels of vanillylmandelic acid (VMA), metanephrine, and catecholamine to rule out a coexisting pheochromocytoma. ${ }^{7,10}$

\section{Imaging}

Ultrasound is helpful for detecting nonpalpable thyroid nodules, for differentiating solid from cystic nodules, and for identifying adjacent lymphadenopathy.

CT and MRI are unnecessary in the routine evaluation of thyroid tumors, except for large, fixed, or substernal lesions.

Scanning the thyroid with ${ }^{123} \mathrm{I}$ or ${ }^{99 \mathrm{~m}} \mathrm{Tc}$ is rarely necessary, unless evaluating patients for "hot" or autonomous thyroid nodules.

Management Thyroid Nodules

\begin{tabular}{|c|c|c|c|}
\hline Diagnosis & Factors Associated With Diagnosis & $\begin{array}{l}\text { Factors That Confirm } \\
\text { The Diagnosis }\end{array}$ & $\begin{array}{c}\text { Factors Associated With A } \\
\text { Worse Prognosis }\end{array}$ \\
\hline \multicolumn{4}{|c|}{ Benign } \\
\hline \multirow[t]{2}{*}{ Colloid } & Multinodular goiter & \multirow[t]{2}{*}{ Surgery } & \multirow[t]{2}{*}{-} \\
\hline & FNA shows colloid and macrophages & & \\
\hline Hyperfunctioning nodule & Hyperthyroidism & ${ }^{131}$ I scan & - \\
\hline \multicolumn{4}{|c|}{ Malignant } \\
\hline \multirow[t]{2}{*}{ Papillary carcinoma } & Radiation exposure & \multirow[t]{2}{*}{ FNA or surgery } & \multirow{2}{*}{$\begin{array}{l}\text { Male gender, age }>40 \mathrm{yr} \text {, size }>3 \\
\mathrm{~cm} \text {, tall-cell variant }\end{array}$} \\
\hline & Previous surgery for papillary carcinoma & & \\
\hline Follicular carcinoma & Follicular cells" by FNA & $\begin{array}{c}\text { Permanent section } \\
\text { pathology }\end{array}$ & $\begin{array}{l}\text { Male gender, age }>40 \mathrm{yr} \text {, size }>3 \\
\mathrm{~cm} \text {, poorly differentiated cell } \\
\text { type }\end{array}$ \\
\hline \multirow[t]{2}{*}{ Medullary carcinoma } & MEN 2A and 2B & Surgery, FNA & \multirow[t]{2}{*}{ MEN 2B and sporadic } \\
\hline & Elevated calcitonin level & $\begin{array}{c}\text { Calcitonin levels ret } \\
\text { oncogene }\end{array}$ & \\
\hline Anaplastic carcino & Rapid progression of tumor mass & FNA & \multirow[t]{2}{*}{ Diagnosis } \\
\hline $\mathrm{ma}$ & Pain, hoarseness & Surgery & \\
\hline
\end{tabular}

Malignant tumors are treated by thyroidectomy, "Simple thyroid cysts resolve with aspiration in approximately 75\% of cases, although some require a second or third aspiration.

If the cyst persists after three attempts at aspiration, unilateral thyroid lobectomy is recommended. Lobectomy is also recommended for cysts greater than $4 \mathrm{~cm}$ in diameter and for complex cysts with solid and cystic components, because the latter have a higher incidence of malignancy $(15 \%)$.

When FNA biopsy is used in complex nodules, the solid portion should be sampled. If a colloid nodule is diagnosed by FNA biopsy, patients should still be observed with serial ultrasound and $\mathrm{Tg}$ measurements.

If the nodule enlarges, repeat FNA biopsy is often indicated. Thyroidectomy should be performed if a nodule enlarges on TSH suppression, causes compressive symptoms, or for cosmetic reasons.

\section{Malignant Thyroid Disease}

Thyroid cancer accounts for less than $1 \%$ of all malignancies ( $2 \%$ of women and $0.5 \%$ of men). Thyroid cancer is responsible for six deaths per 1 million persons annually. ${ }^{7,8}$ Most patients present with a palpable swelling in the neck, which initiates assessment through a combination of history, physical examination, and FNA biopsy.

\section{Papillary Carcinoma}

$80 \%$ of all thyroid malignancies in iodine-sufficient areas; predominant thyroid cancer in children and individuals exposed to external radiation; 2:1 female:male ratio; Mean age at presentation is 30 to 40 years; ${ }^{14}$ Most patients are euthyroid and present with a slow-growing painless mass in the neck. Dysphagia, dyspnea, and dysphonia are usually associated with locally advanced invasive disease, ${ }^{13}$ Lymph node metastases are common, especially in children and young adults; Diagnosis is established by FNA biopsy ${ }^{8}$ of the thyroid mass or lymph node; Distant metastases are uncommon at initial presentation, but may ultimately develop in up to $20 \%$ of patients. The most common sites are the lungs, followed by bone, liver, and brain. ${ }^{13,14}$ 


\section{International Journal of Science and Research (IJSR) \\ ISSN (Online): 2319-7064}

Index Copernicus Value (2015): 78.96 | Impact Factor (2015): 6.391

Pathology

- On gross examination, PTCs are generally hard and whitish. ${ }^{14}$

- Macroscopic calcification, necrosis, or cystic change may be apparent.

- Histologically papillary projections, a mixed pattern of papillary and follicular ${ }^{7}$ structures, or a pure follicular pattern (follicular variant).

- Cells are cuboidal with pale, abundant cytoplasm, "grooving," crowded nuclei, and intranuclear cytoplasmic inclusions, leading to the designation of Orphan Annie nuclei, which allows diagnosis by FNA biopsy.

- Psammoma bodies, which are microscopic, calcified deposits representing clumps of sloughed cells, may be present $^{8}$.

- Multifocality is common in papillary carcinoma and may be present in up to $85 \%$ of cases on microscopic examination.

\section{Prognostic Indicators}

AGES scoring system, which incorporates age, histologic grade, extrathyroidal invasion and metastases, and tumor size to predict the risk of dying from papillary cancer. ${ }^{7}$

The MACIS scale incorporates distant metastases, age at presentation, and completeness of original surgical resection, extra thyroidal invasion, and size of original lesion (in centimetres) and classifies patients into four riskgroups based on their scores ${ }^{8}$.

AMES system classify differentiated thyroid tumors into low- and high-risk groups using $a$ ge (men $<40$ years, women $<50$ years), metastases, extrathyroidal spread, and size of tumors $(5 \mathrm{~cm})$.

\section{TNM system, (tumor, nodal status, metastases,}

\section{Surgical Treatment}

- Total or near-total thyroidectomy.

- When patients are found to have a minimal papillary thyroid carcinoma in a thyroid specimen removed for other reasons, unilateral thyroid lobectomy and isthmusectomy

\section{Follicular Carcinoma}

$10 \%$ of thyroid cancers and occur more commonly in iodinedeficient areas; female: male ratio of $3: 1$ with mean age at presentation of 50 years. ${ }^{15}$

Present as solitary thyroid nodules, occasionally with a history of rapid size increase, and long-standing goiter. Pain, cervical lymphadenopathy is uncommon.

FNA biopsy is unable to distinguish benign follicular lesions from follicular carcinomas. Therefore, preoperative diagnosis of cancer $^{20,21}$ is difficult unless distant metastases are present
Large follicular tumors $(>4 \mathrm{~cm})$ in older men are more likely to be malignant.

\section{Pathology}

Follicular carcinomas are usually solitary lesions, the majority of which are surrounded by a capsule. ${ }^{14}$

Histologically, follicles are present, but the lumen may be devoid of colloid. Architectural patterns depend on the degree of differentiation demonstrated by the tumor.

Malignancy is defined by the presence of capsular and vascular invasion. Minimally-invasive tumors appear grossly encapsulated but have evidence of microscopic invasion through the tumor capsule and/or invasion into small- to medium-size vessels (venous caliber) in or immediately outside the capsule, but not within the tumor.

Widely invasive tumors demonstrate evidence of largevessel invasion and/or broad areas of tumor invasion through the capsule.

\section{Hurthle Cell Carcinoma}

- $3 \%$ of all thyroid malignancies.

- Under the World Health Organization classification, Hürthle cell carcinomas are considered to be a subtype of follicular thyroid cancer ${ }^{3}$.

- Like follicular cancers, Hürthle cell cancers are characterized by vascular or capsular invasion, and therefore cannot be diagnosed by FNA biopsy

- Tumors contain sheets of eosinophilic cells packed with mitochondria, which are derived from the oxyphilic cells of the thyroid gland. ${ }^{7,8}$

- Management is similar to that of follicular neoplasms, with lobectomy and isthmusectomy being sufficient surgical treatment for unilateral Hürthle cell adenomas.

\section{Postoperative Management}

Thyroid Hormone \& Thyroglobulin Measurement, Radioiodine Therapy.

External Beam Radiotherapy and Chemotherapy.

\section{Medullary Carcinoma}

- Mtcs account for about 5\% of thyroid malignancies. ${ }^{7,13}$

- Arise from the parafollicular or C cells of the thyroid, which, in turn, are derived from the ultimobranchial bodies. $^{22}$

- C cells secrete calcitonin, a 32-amino-acid polypeptide.

- $25 \%$ occur within the spectrum of several inherited syndromes such as familial medullary thyroid cancer, MEN2A, and MEN2B.

- Secondary to germline mutations in the RET protooncogene. ${ }^{7}$ 


\section{International Journal of Science and Research (IJSR) \\ ISSN (Online): 2319-7064}

Index Copernicus Value (2015): 78.96 | Impact Factor (2015): 6.391

\begin{tabular}{|l|l|l|}
\hline \multicolumn{3}{|c|}{ Clinical and Genetic Features of Medullary Thyroid Cancer Syndromes } \\
\hline Syndrome & Manifestations & Ret Mutations \\
\hline MEN2A & $\begin{array}{l}\text { MTC, pheochromocytoma, primary } \\
\text { hyperparathyroidism, lichen planus, amyloidosis }\end{array}$ & Exon 10: codons 609, 611, 618, 620 \\
\hline MEN2B & $\begin{array}{l}\text { Exon 11: codon 634 (more commonly associated with } \\
\text { pheochromocytoma and primary hyperparathyroidism) }\end{array}$ \\
\hline Familial MTC & $\begin{array}{l}\text { MTC, pheochromocytoma, marfanoid habitus, } \\
\text { mucocutaneous ganglioneuromatosis }\end{array}$ & exon 16: codon 918 \\
\hline $\begin{array}{l}\text { MEN2A and } \\
\text { Hirschsprung's disease }\end{array}$ & $\begin{array}{l}\text { MTC, pheochromocytoma, primary } \\
\text { hyperparathyroidism, Hirschsprung's disease }\end{array}$ & Codons 609,611,618, 620, and 634 \\
\hline
\end{tabular}

Patients with MTC often present with a neck mass that may be associated with palpable cervical lymphadenopathy (15 to $20 \%)$.

Local pain or aching is more common in patients with these tumors, and local invasion may produce symptoms of dysphagia, dyspnea, or dysphonia. Distant blood-borne metastases to the liver, bone (frequently osteoblastic), and lung occur later in the disease.

The female:male ratio is $1.5: 1$.

Most patients present between 50 and 60 years of age, although patients with familial disease present at a younger age.

\section{Anaplastic Carcinoma}

Anaplastic carcinoma accounts for approximately $1 \%$ of all thyroid malignancies

Women are more commonly affected, and the majority of tumors present in the seventh and eighth decades of life. ${ }^{7,19}$

\section{Pathology}

On gross inspection, anaplastic tumors are firm and whitish in appearance. Microscopically, sheets of cells with marked heterogeneity are seen. ${ }^{22}$ Cells may be spindle-shaped, polygonal, or large, multinucleated cells. Foci of more differentiated thyroid tumors, either follicular or papillary, may be seen, suggesting that anaplastic tumors arise from more well-differentiated tumors. One should confirm that the tumor is not an MTC or a small-cell lymphoma because the prognosis varies considerably.

\section{Lymphoma}

- Less than $1 \%$ of thyroid malignancies ${ }^{21,22}$ and most are of the non-Hodgkin's B-cell type.

- Patients usually present with symptoms similar to those of patients with anaplastic carcinoma, although the rapidly enlarging neck mass often is painless. Patients may present with acute respiratory distress

\section{(HASHIMOTO'S) THYROIDITIS}

- Autoimmune process that is thought to be initiated by the activation of $\mathrm{CD} 4+\mathrm{T}$ (helper) lymphocytes with specificity for thyroid antigens. ${ }^{12,13}$

- Hypothyroidism results not only from the destruction of thyrocytes by cytotoxic $\mathrm{T}$ cells, but also from auto antibodies. $^{10}$

\section{Metastatic Carcinoma}

The thyroid gland is a rare site of metastases from other cancers, including kidney, breast, lung, and melanoma. ${ }^{15}$ Clinical examination and a review of the patient's history often suggest the source of the metastatic disease, and FNA biopsy usually provides definitive diagnosis ${ }^{22}$. Resection of the thyroid, usually lobectomy, may be helpful in many patients, depending on the status of their primary tumor.

Indications for Interventional Procedures

\begin{tabular}{|c|c|c|c|}
\hline Procedure & Advantage & Disadvantage Or Complications & Indication \\
\hline \multirow[t]{2}{*}{$\begin{array}{c}\text { Fine-needle aspiration } \\
\text { (FNA) }\end{array}$} & \multirow[t]{2}{*}{$\begin{array}{l}\text { Accurate diagnosis of } \\
\text { malignancy }\end{array}$} & Cannot confirm benign diagnosis & $\begin{array}{l}\text { Tissue diagnosis of ultrasound- } \\
\text { determined solid nodule }\end{array}$ \\
\hline & & Capsular hemorrhage & Previous —andiagnostic" result \\
\hline Open biopsy & Direct visualization & $\begin{array}{l}\text { Requires an operating room, possibly general } \\
\text { anesthesia }\end{array}$ & $\begin{array}{l}\text { Complex case in which FNA has } \\
\text { failed to give a diagnosis }\end{array}$ \\
\hline $\begin{array}{l}\text { Nodulectomy" (less } \\
\text { than a lobectomy) }\end{array}$ & None & $\begin{array}{l}\text { Difficult second operation to complete the } \\
\text { lobectomy if a diagnosis of cancer is made }\end{array}$ & None \\
\hline \multirow[t]{2}{*}{$\begin{array}{l}\text { Lobectomy (with } \\
\text { isthmectomy) }\end{array}$} & \multirow{2}{*}{$\begin{array}{c}\text { Lower rates of } \\
\text { hypocalcemia and nerve } \\
\text { damage }\end{array}$} & $\begin{array}{l}\text { May require completion thyroidectomy if a } \\
\text { diagnosis of cancer is made }\end{array}$ & Strong suspicion of benign disease \\
\hline & & & Well-differentiated cancer $<1 \mathrm{~cm}$ \\
\hline
\end{tabular}

\section{THYROIDECTOMY}

Patient must be appropriately positioned with the neck extended. $^{6}$ A transverse incision ${ }^{9}$ is made about two fingerbreadths above the clavicular heads. ${ }^{9}$

The skin incision is carried through subcutaneous fat and the platysmal muscle, ${ }^{2,3}$ and superior and inferior flaps are dissected in a bloodless plane beneath the platysmal layer. ${ }^{6,9}$ The anterior jugular veins are identified, and any that are crossing or running along the midline can be divided. Dissection between the sternohyoid and the sternothyroid muscles gains exposure to the lateral and deeper structures. ${ }^{19}$ Exposure of these lateral structures is enhanced by placing medial traction on the thyroid lobe on the side being

\section{Volume 6 Issue 1, January 2017




\section{International Journal of Science and Research (IJSR) \\ ISSN (Online): 2319-7064 \\ Index Copernicus Value (2015): 78.96 | Impact Factor (2015): 6.391}

dissected. Care must be taken to divide the middle thyroid vein before it is placed under excessive traction by this manoeuvre. With lateral retraction of the muscles and medial retraction of the thyroid lobe, the common carotid is quickly defined. In the case of complicated lateral thyroid masses, ${ }^{18}$ lymphadenopathy, or previous surgery, it may be necessary to gain exposure laterally by dividing the sternohyoid and sternothyroid muscles. Total thyroidectomy involves division ${ }^{1,6}$ of all thyroid tissue between the entrance of the recurrent laryngeal nerves bilaterally at the ligament of Berry, and it results in complete removal of all visible thyroid tissue. ${ }^{2,3}$ Near-total thyroidectomy involves complete dissection on one side while leaving a remnant of thyroid tissue laterally on the contralateral side, which incorporates the parathyroids. Subtotal thyroidectomy ${ }^{4,9}$ leaves a rim of thyroid tissue bilaterally to ensure parathyroid viability and avoid entrance of the recurrent laryngeal nerves into the larynx

\section{Results and Discussion}

A study is designed for the data collected during the study period and various epidemiological and other statistical details are analysed, results calculated and Graphs given at appropriate places to make easy understanding. Of the 100 patients who underwent our study, there are 10 males and 90 females showing female preponderance (sex ratio $=\mathrm{M} ; \mathrm{F}$ $1 ; 10)$. There were patients ranging from lowest age of $19 \mathrm{yrs}$ to highest age of 65 years.-The following statistics are calculated. Mean Age $=37.8$ Years. Median Age $=35$ Years

Table 1: Age stratification data shows following details:

\begin{tabular}{|c|c|c|}
\hline Age Group & No. of Patients & Percentage \\
\hline $11-19$ & 1 & $1 \%$ \\
\hline $20-29$ & 28 & $28 \%$ \\
\hline $30-39$ & 30 & $30 \%$ \\
\hline $40-49$ & 22 & $22 \%$ \\
\hline $50-59$ & 15 & $15 \%$ \\
\hline $60-70$ & 4 & $4 \%$ \\
\hline Total & 100 & $100 \%$ \\
\hline
\end{tabular}

The above data shows that $3^{\mathrm{RD}} \& 4^{\mathrm{TH}}$ decades(20-39 years) are the most common age group for thyroid nodules $(58 \%)$ closely followed by $5^{\text {th }}$ decade ( $40-49$ years) which is $22 \%$.

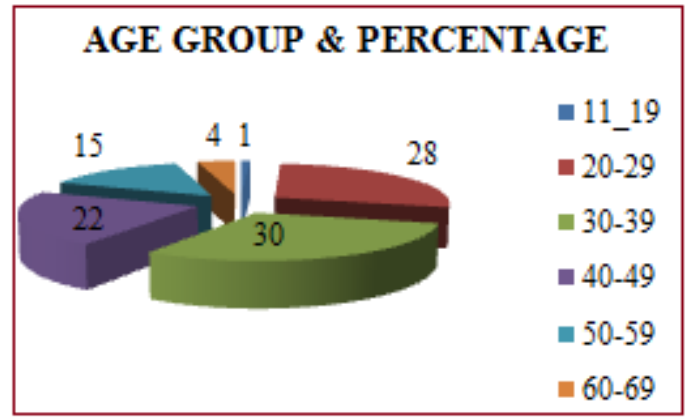

Chief Presenting Complaints

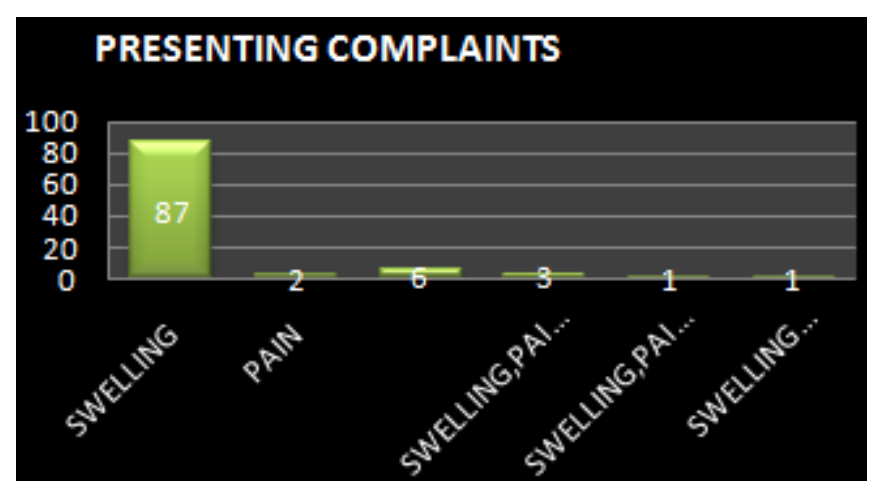

Table No 2

\begin{tabular}{|l|l|}
\hline Complaint & No of Patients \\
\hline Swelling & 87 \\
\hline Pain & 2 \\
\hline Swelling and Pain & 6 \\
\hline Swelling, Pain, Dyspnoea & 3 \\
\hline Swelling, Pain , Hoarseness of Voice & 1 \\
\hline Swelling and Hoarseness of Voice & 1 \\
\hline
\end{tabular}

\section{Table No 3}

Solitary nodule presented clinically of varying sizes from 2 $\mathrm{cm}$ to $9 \mathrm{~cm}$. Clinically diagnosed solitary nodular goiters found to have impalpable nodules diagnosed by USG and as intraop finding.

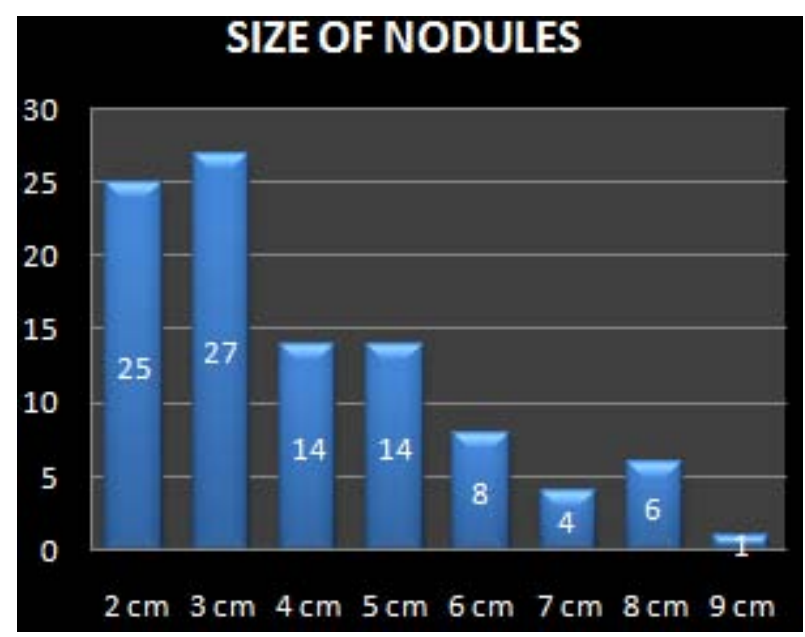

Table No 4

\begin{tabular}{|c|c|}
\hline Male & Female \\
\hline 10 & 90 \\
\hline
\end{tabular}

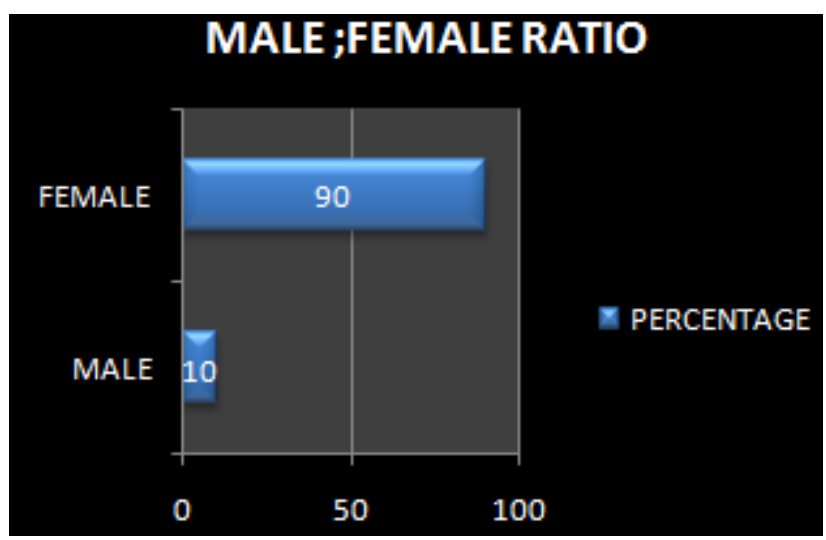




\section{International Journal of Science and Research (IJSR) \\ ISSN (Online): 2319-7064 \\ Index Copernicus Value (2015): 78.96 | Impact Factor (2015): 6.391}

Table No 5

FNAC was found to have a sensitivity of $86 \%$ and a specificity of $91 \%$. Follicular adenomas and carcinoma cannot be differentiated .FNAC are repeated for inconclusive results.USG guided FNAC is not done. Two cases of papillary ca were diagnosed and confirmed by FNAC One suspected papillary ca is found confirmed in post-op biopsy. In three suspected follicular neoplasms only one patient confirmed positive in biopsy.

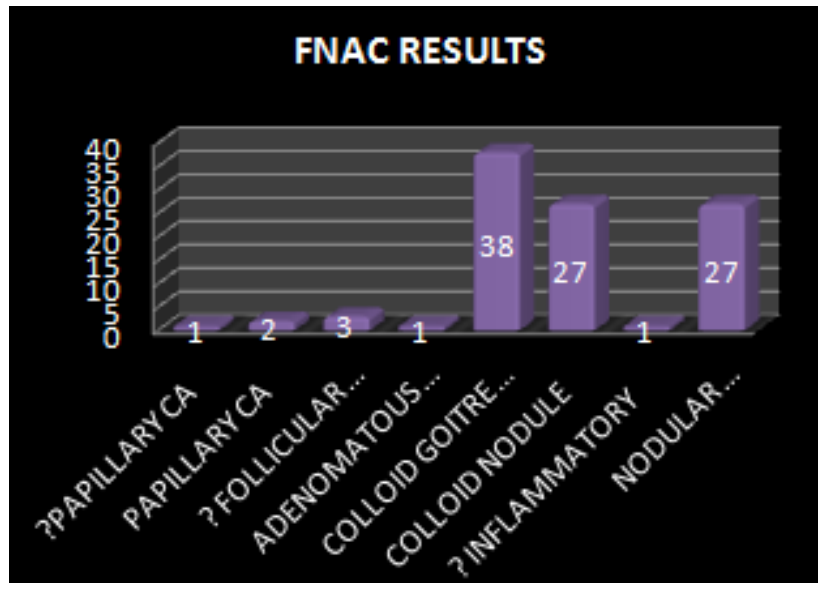

Table No 6

USG preoperatively done and clinically diagnosed solitary nodule thyroid patients found to have impalpable small nodes bilaterally.

\begin{tabular}{|l|c|}
\hline Solitary nodule thyroid & 69 \\
\hline Multiple nodules bilaterally- dominant & 30 \\
\hline Simple cyst & 1 \\
\hline
\end{tabular}

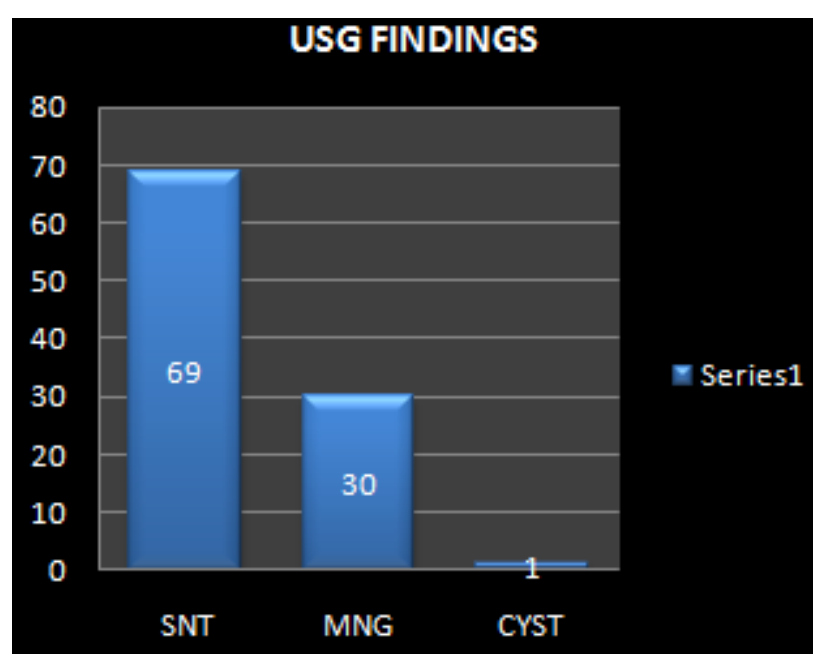

Table 7

\begin{tabular}{|l|l|}
\hline Right lobe & $41 \%$ \\
\hline Left lobe & $28 \%$ \\
\hline Bilateral & $30 \%$ \\
\hline
\end{tabular}

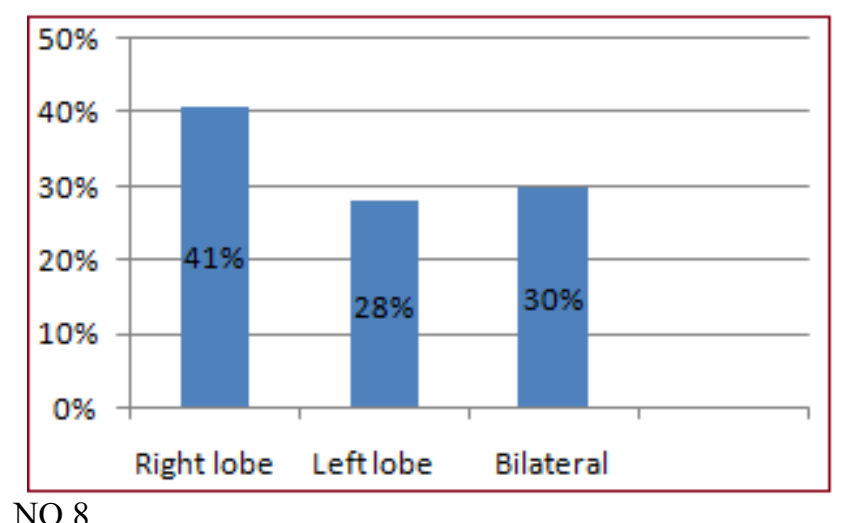

For most of the solitary nodules Rt or Lt hemithyroidectomy is performed

Subtotal thyroidectomy is performed for multinodular goitres with dominant nodule

Near total and total thyroidectomy is done for malignant thyroid nodules and one suspected case of follicular neoplasm. Cystectomy is performed for simple cysts

\begin{tabular}{|l|l|}
\hline Hemi thyroidectomy & 64 \\
\hline Subtotal thyroidectomy & 29 \\
\hline Near total thyroidectomy & 1 \\
\hline Total thyroidectomy & 4 \\
\hline Cystectomy & 2 \\
\hline
\end{tabular}

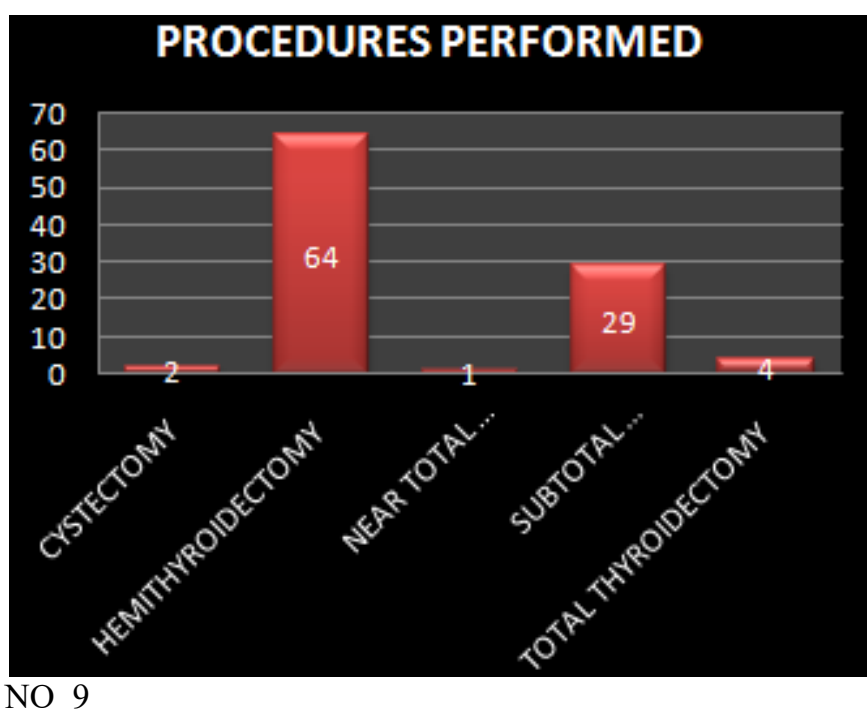

Post op biopsy revealed malignant disease in 4 cases Hashimotos thyroiditis in 5 case and benign conditions for the remaining cases.

An incidence of $4 \%$ of malignancy is found in the study.

\begin{tabular}{|l|l|}
\hline Benign & 96 \\
\hline Malignant & 4 \\
\hline
\end{tabular}




\section{International Journal of Science and Research (IJSR) \\ ISSN (Online): 2319-7064 \\ Index Copernicus Value (2015): 78.96 | Impact Factor (2015): 6.391}

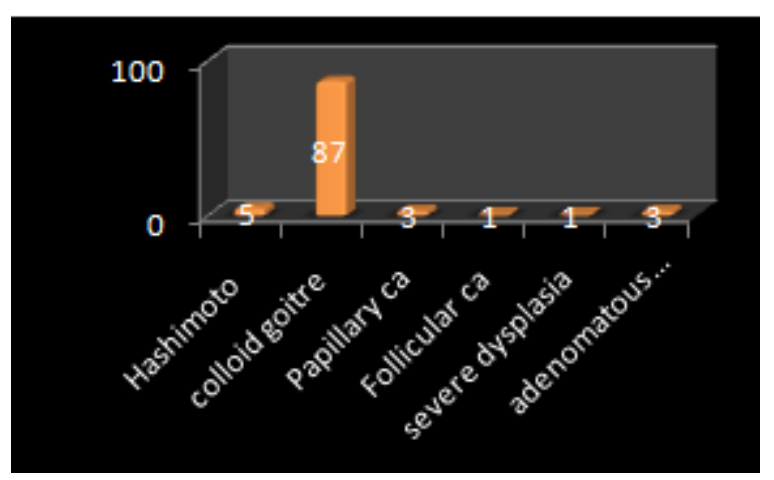

During the past 2 decades, the widespread use of ultrasonography (US) for evaluation of thyroid disease has resulted in a dramatic increase in the prevalence of clinically inapparent thyroid nodules, estimated at $20 \%$ to $76 \%$ in the general population. $20 \%$ to $48 \%$ of patients with a single palpable thyroid nodule are found to have additional nodules when investigated by US. As a consequence, we are now facing an epidemic of thyroid nodules; the prevalence is similar to that reported in autopsy data, $50 \%$, in patients with no history of thyroid disease.

In our study $30 \%$ of clinically palpable and diagnosed solitary nodular goitres found to have multiple small nodules in USG and intraoperative findings which correlates with the previous study

\section{Conclusion}

Solitary nodule thyroid is the commonest presentation in thyroid disorders. 20-39 years are the commonest age group ; $30 \%$ of clinically solitary nodules found to be dominant nodules in MNG on USG and intraop findings. Most of the disorders are benign. Malignancy accounts for $4 \%$ of cases. Incidence is more common in females M:F 1:9 Most cases are diagnosed preoperatively and confirmed by biopsy. Cystectomy, hemithyroidectomy,.subtotal thyroidectomy, neartotal thyroidectomy, total thyroidectomy are the various surgeries done for clinically presenting solitary nodules in thyroid. Incidence of neuropraxia in recurrent laryngeal nerve which recovered completely is $29 \%$. No bilateral nerve palsy encountered. No incidence wound infection seen.

\section{References}

[1] COURTNEY .M. TOWNSEND - SABISTON TEXT BOOK OF SURGERY - 18 th Edition vol I pages 917 $-954$

[2] R.C.G. RUSSELL \& N.S. WILLIAMS. BAILEY \& LOVE - Short practice of Surgery - 25th Edition pages 771-806

[3] Josef E fischer Mastery of Surgery by Lloyd M.Nyhus. $5^{\text {th }}$ edition Indian reprint 2008,,vol Chapters 33,34,\& 35

[4] A.Cushieri, G.R.Giles A.R.Moossa Essential surgical practice $-4^{\text {th }}$ edition pages $95-109$

[5] F.Charles Brunicardi SCHWARTZ'S PRINCIPLES OF SURGERY - 8 th Edition pages 1395-1439

[6] FARQUHARSON'S TEXT BOOK OF OPERATIVE GENERAL SURGERY9 th edition 159-163
[7] American joint committee on cancer.: AJCC cancer STAGING MANUAL. 6th ed. New York, NY: Springer, 2002

[8] VINCENT. T . DEVITA JR. - CANCER PRINCIPLES AND PRACTICE OF ONCOLOGY

[9] Carol E H Scott Conner Chassin s operative strategy in general surgery 3 rd edition pages $894-904$

[10]AACE/AME Guidelines ENDOCRINE PRACTICE Vol 12 No. 1 January/February 200663

[11] Fine-needle aspiration biopsy of thyroid nodules: advantages, limitations, and effects. Mayo Clin Proc. 1994 Jan; 69(1):44-9.

[12] Fine-needle aspiration biopsy of the thyroid: an appraisal. Ann Intern Med. 1993 Feb 15; 118(4):282-9

[13] Fine-needle aspiration biopsy of thyroid nodules: advantages, limitations, and effect. Mayo Clin Proc. 1994 Jan; 69(1):44-9.

[14] Papillary and follicular thyroid carcinoma. N Engl J Med 1998; 338:297-306.

[15] Follicular thyroid carcinoma: Histology and prognosis. Cancer 2004; 100:1123-1129.

[16]Role of repeated fine-needle aspiration of thyroid nodules with benign cytologic features. Endocr Pract. 2001 Jul-Aug; 7(4):237-43

[17] Thyroid nodules: does the suspicion for malignancy really justify the increased thyroidectomy rates? Surg Oncol. 2006 Jul; 15(1):43-55.

[18] Fine needle aspiration of thyroid nodules. Determinants of insufficiency rate and malignancy yield at thyroidectomy. Acta Cytol. 1996 Nov-Dec; 40(6):117683.

[19] Surgical management of the thyroid nodule: patient selection based on the results of fine-needle aspiration cytology. Laryngoscope. 1992 Dec; 102(12 Pt 1):13536.

[20] Fine needle aspiration biopsy of thyroid nodules. Arch Dis Child. 2001 Oct; 85(4):313-7

[21] Thyroid fine-needle aspiration biopsy: progress, practice, and pitfalls. Endocr Pract. 2003 Mar-Apr; $9(2): 128-36$.

[22] The frequency of malignant disease in cytological group of suspected cancer (ultrasound-guided fine-needle aspiration biopsy of non palpable thyroid nodules)] Medicina (Kaunas). 2008; 44(3):189-9

[23] Ultrasonography-guided fine-needle aspiration of thyroid incidentaloma: correlation with pathological findings. Clin Endocrinol (Oxf). 2004 Jan; 60(1):21-8.

[24] Current status of fine needle aspiration for thyroid nodules. Adv Surg. 2006; 40:223-38. 